\title{
Chest physiotherapy improves regional lung volume in ventilated children
}

Bronagh McAlinden ${ }^{1,2}$, Suzanne Kuys ${ }^{1}$, Andreas Schibler ${ }^{3}$ and Judith L. Hough ${ }^{1,2,3^{*}}$ (D)

Keywords: Electrical impedance tomography, Chest physiotherapy, Ventilation distribution, Paediatric, Suction

\section{Dear Editor,}

Chest physiotherapy (CPT) is widely used to improve distribution of ventilation and gas exchange in the management of mechanically ventilated infants and children with lung disease [1]. The mechanism by which CPT works is not well understood due to the lack of appropriate outcome measures capable of quantifying changes in ventilation distribution. Electrical impedance tomography (EIT), a non-invasive means of measuring ventilation distribution, is a potential tool to measure CPT effects on lung function in ventilated infants and children [2]. We describe, using EIT, the effect of CPT compared with receiving endotracheal suction only on ventilation distribution and gas exchange in children.

A secondary analysis of data previously collected within a prospective randomised controlled trial investigating the effect of recruitment manoeuvres on 60 ventilated children following endotracheal (ETT) suction was conducted in a tertiary paediatric intensive care unit [3]. Children who, based on clinical indication, had received CPT for intensive airway clearance were compared to children receiving suction only. CPT compromised any combination of manual techniques and manual hyperinflation followed by open ETT suctioning [1].
Ventilation distribution (amplitude, global ventilation inhomogeneity, geometric centre) and endexpiratory lung volume (EELV) were measured using EIT (Gottingen GoeMF II, VIASYS Healthcare, Hochberg, Germany) prior to CPT and suction, and then 30, 60 and 120 min post-intervention. Gas exchange (arterial blood gases and oxygen saturation) and physiological variables (heart rate and respiratory rate) were recorded.

Linear mixed models were used to determine differences and interactions between those who did and did not receive CPT, over the four time points, for each dependent variable. As this was a secondary analysis of data, we also examined interactions with recruitment manoeuvres and found that the effects of CPT were independent of lung recruitment manoeuvres $(p>0.05)$.

Seventeen participants (28\%) received CPT (28.7 \pm 49.3 months), and forty-three participants (72\%) received no CPT $(47.8 \pm 55.8$ months) $(p=0.22)$. Ventilator settings remained constant pre- and post-intervention. No differences were found at baseline between the two groups for all parameters except $\mathrm{PaCO}_{2}$, which was significantly higher in the CPT group (Table 1), indicative

\footnotetext{
* Correspondence: judith.hough@acu.edu.au

${ }^{1}$ School of Allied Health, Australian Catholic University, Banyo, QLD 4014,

Australia

${ }^{2}$ Mater Health, South Brisbane 4101, Australia

Full list of author information is available at the end of the article
} 
Table 1 Participant characteristics for the chest physiotherapy (CPT) group and routine airway clearance group at baseline: mean (SD)

\begin{tabular}{|c|c|c|c|}
\hline Characteristic & CPT $(n=17)$ & Routine airway clearance $(n=43)$ & Sig ( $p$ value) \\
\hline Age (months) & $28.7(49.3)$ & $47.8(55.8)$ & 0.221 \\
\hline Weight (kg) & $11.1(11.4)$ & $16.6(14.2)$ & 0.163 \\
\hline ETT size (mm) & $4.2(1.1)$ & $4.5(1.2)$ & 0.328 \\
\hline Baseline $\mathrm{FiO}_{2}$ & $0.4(0.1)$ & $0.4(0.1)$ & 0.834 \\
\hline Baseline $\mathrm{PaO}_{2}(\mathrm{mmHg})$ & $89.4(30.2)$ & $96.4(29.6)$ & 0.411 \\
\hline Baseline $\mathrm{PaCO}_{2}(\mathrm{mmHg})$ & $58.7(11.1)$ & $48.6(11.5)$ & ${ }^{*} 0.003$ \\
\hline Baseline P/F ratio & $282.3(165.9)$ & $286.9(109.6)$ & 0.901 \\
\hline Baseline RR (breaths/min) & $34.7(17.5)$ & $28.7(11.2)$ & 0.121 \\
\hline Baseline PEEP $\left(\mathrm{cmH}_{2} \mathrm{O}\right)$ & $7.0(2.4)$ & $7.8(2.2)$ & 0.239 \\
\hline Baseline PIP $\left(\mathrm{cmH}_{2} \mathrm{O}\right)$ & $21.1(7.0)$ & $21.2(4.3)$ & 0.932 \\
\hline Baseline MAP $\left(\mathrm{cmH}_{2} \mathrm{O}\right)$ & $11.0(3.6)$ & $11.0(3.0)$ & 0.939 \\
\hline Cuffed ETT, n (\%) & $14(92 \%)$ & $38(88 \%)$ & 0.834 \\
\hline \multicolumn{4}{|l|}{ Ventilation mode, number (\%) } \\
\hline SIMV & $16(94 \%)$ & 39 (91\%) & 0.424 \\
\hline PCV & 0 & $1(2.3 \%)$ & - \\
\hline PSV & $1(6 \%)$ & $2(4.7 \%)$ & - \\
\hline CPAP & 0 & $1(2.3 \%)$ & - \\
\hline \multicolumn{4}{|l|}{ Randomised groups, number (\%) } \\
\hline Control & $7(41 \%)$ & $13(30 \%)$ & \\
\hline Double PEEP recruitment & $4(24 \%)$ & $16(37 \%)$ & \\
\hline Stepwise recruitment & $6(35 \%)$ & $14(33 \%)$ & \\
\hline \multicolumn{4}{|l|}{ Reason for intubation, number (\%) } \\
\hline Primary respiratory pathology\# & $10(59 \%)$ & $21(49 \%)$ & 0.226 \\
\hline Secondary respiratory pathology^ & $7(41 \%)$ & 22 (51\%) & - \\
\hline
\end{tabular}

Abbreviations: CPAP continuous positive airway pressure, ETT endotracheal tube, $\mathrm{FiO}_{2}$ fraction of inspired oxygen, $M A P$ mean airway pressure, $\mathrm{PaO} \mathrm{O}_{2}$ partial pressure of arterial oxygen, $P C V$ pressure-controlled ventilation, $P E E P$ positive end-expiratory pressure, PIP peak inspiratory pressure, $P S V$ pressure support ventilation, RR respiratory rate, $S D$ standard deviation, SIMV synchronised intermittent mandatory ventilation

\#Primary respiratory pathology = bronchiolitis and pneumonia, asthma, influenza, immersion injury

$\wedge$ Secondary respiratory pathology = airway management, sepsis, seizure management, tick paralysis, gastrointestinal bleeding, trauma, neurological injury, GuillainBarre syndrome, ingestion and renal failure

${ }^{*} p<0.05$

of ventilation maldistribution, more extensive lung disease and was a clinical trigger for CPT. Similar to previous studies, the differences we found in $\mathrm{CO}_{2}$ between $\mathrm{CPT}$ and suction remained consistent after intervention $[4,5]$.

In the CPT group, EELV changes at all measurement points were significantly greater $(p<0.001)$, indicative of either recruitment of atelectatic alveoli or further distention of already ventilated alveoli [6] (Table 2). The increase in EELV as a result of lung recruitment secondary to secretion removal is supported by the finding of movement of the geometric centre toward the dependent lung in the children receiving CPT $(p=0.005)$, indicating improved ventilation posteriorly. CPT mobilises secretions from peripheral airways of the lung where the secretions can cause collapse of distal alveoli, whereas suction removes secretions from the proximal airways and has minimal effect on peripheral secretion clearance. A higher global inhomogeneity index after CPT ( $p=$ $0.017)$ reflected greater variations in ventilation distribution and regionally opening lung fields.

No differences for global amplitude $(p=0.74)$ between those receiving CPT and those who did not were found, which is not unexpected as all participants were fully volume-controlled ventilated.

Improvements in EELV, geometric centre and global inhomogeneity occurred within $30 \mathrm{~min}$ of receiving CPT $(p<0.01)$ suggesting that by facilitating secretion clearance, CPT can result in immediate changes in 
Table 2 Difference between pooled routine airway clearance and chest physiotherapy data for each outcome measure, and the interaction effect of recruitment manoeuvres: mean difference, standard error (SE), significance and 95\% confidence intervals (Cl) (linear mixed models)

\begin{tabular}{|c|c|c|c|c|c|}
\hline & \multicolumn{4}{|c|}{ Chest physiotherapy (CPT) minus routine airway clearance main effect } & \multirow{2}{*}{$\begin{array}{l}\text { CPT*recruitment interaction effect } \\
\text { Significance }\end{array}$} \\
\hline & Mean difference & SE & Significance & $95 \% \mathrm{Cl}$ & \\
\hline \multicolumn{6}{|c|}{ Ventilation distribution (relative impedance $\Delta$ ) } \\
\hline Global Amp & -0.004 & 0.012 & 0.745 & $-0.027-0.020$ & 0.479 \\
\hline Global EELV & 0.084 & 0.018 & *0.000 & $0.047-0.121$ & 0.293 \\
\hline Anterior EELV & 0.047 & 0.015 & *0.003 & $0.017-0.078$ & 0.931 \\
\hline Posterior EELV & 0.107 & 0.027 & *0.000 & $0.053-0.160$ & 0.402 \\
\hline Global inhomogeneity index & 0.043 & 0.018 & $*^{*} 0.017$ & $0.008-0.078$ & 0.230 \\
\hline Geometric centre (\%) & -3.613 & 1.241 & $* 0.005$ & -6.097 to -1.129 & 0.833 \\
\hline \multicolumn{6}{|l|}{ Gas exchange } \\
\hline $\mathrm{PaO}_{2}(\mathrm{mmHg})$ & -7.861 & 6.186 & 0.209 & $-20.243-4.521$ & 0.217 \\
\hline $\mathrm{PaCO}_{2}(\mathrm{mmHg})$ & 9.615 & 3.013 & $*^{*} 0.002$ & $3.610-15.620$ & 0.110 \\
\hline PF ratio & -56.663 & 32.220 & 0.084 & $-121.210-7.885$ & 0.250 \\
\hline $\mathrm{FiO}_{2}$ & 0.040 & 0.024 & 0.106 & $-0.009-0.089$ & 0.279 \\
\hline $\mathrm{SpO}_{2}$ & -0.175 & 0.790 & 0.825 & $-1.763-1.412$ & 0.095 \\
\hline $\mathrm{SpO}_{2} / \mathrm{FiO}_{2}$ & -33.565 & 21.584 & 0.126 & $-76.832-9.703$ & 0.195 \\
\hline \multicolumn{6}{|l|}{ Physiological state } \\
\hline Respiratory rate (bpm) & 5.886 & 3.190 & 0.070 & $-0.495-12.267$ & ${ }^{*} 0.001$ \\
\hline Heart rate (bpm) & 4.869 & 7.021 & 0.491 & $-9.202-18.940$ & *0.048 \\
\hline
\end{tabular}

Abbreviations: $A m p$ amplitude, bpm breaths/beat per minute, $\mathrm{Cl}$ confidence interval, $E E L V$ end-expiratory level volume, $\mathrm{FiO}_{2}$ fraction of inspired oxygen, $\mathrm{HR}$ heart rate, $\mathrm{PaO}_{2}$ partial pressure of arterial oxygen, $\mathrm{PaCO}_{2}$ partial pressure of arterial carbon dioxide, $P F \mathrm{PaO}_{2} / \mathrm{FiO}_{2}, \mathrm{SE}$ standard error, $\mathrm{SpO} \mathrm{O}_{2}$ oxygen saturation, $\triangle$ change ${ }^{*} p<0.05$

ventilation distribution, which are sustained for up to 120 min and identifiable using EIT.

We have shown that EIT can detect regional changes in lung function as a result of CPT in ventilated infants and children, making it a potential clinical tool to measure the effects of CPT and for focusing CPT to areas of concern.

\section{Abbreviations}

CPT: Chest physiotherapy; EELV: End-expiratory lung volume; EIT: Electrical impedance tomography; ETT: Endotracheal tube; $\mathrm{PaCO}_{2}$ : Partial pressure of arterial carbon dioxide

\section{Acknowledgements}

Not applicable

\section{Authors' contributions}

$J \mathrm{H}, \mathrm{BM}, \mathrm{SK}$ and AS developed and revised the manuscript. BM performed the CPT. JH and BM analysed the patient data. All authors read and approved the final manuscript.

\section{Funding}

Funding received for this research project was a Mater Children's Hospital Golden Casket Seeding Grant, providing time off clinical work to undertake the study.

\section{Availability of data and materials}

The datasets used and/or analysed during the current study are available from the corresponding author on reasonable request.
Ethics approval and consent to participate

Ethical clearance was obtained through the Mater Misericordiae Human Research Ethics Committee (HREC/17/MHS/72) and the ACU HREC (2017153R). Written consent was received for all participants of the RCT through physical consent forms prior to research commencement.

\section{Consent for publication}

Not applicable

\section{Competing interests}

The authors declare that they have no competing interests.

\section{Author details}

${ }^{1}$ School of Allied Health, Australian Catholic University, Banyo, QLD 4014, Australia. ${ }^{2}$ Mater Health, South Brisbane 4101, Australia. ${ }^{3}$ Paediatric Critical Care Research Group, Children's Health Research Centre - The University of Queensland, South Brisbane 4101, Australia.

Received: 7 April 2020 Accepted: 5 July 2020

Published online: 16 July 2020

References

1. McCord J, Krull N, Kraiker J, Ryan R, Duczeminski E, Hassall A, et al. Cardiopulmonary physical therapy practice in the paediatric intensive care unit. Physiother Can. 2013;65(4):374-7.

2. Hough $J$, Shearman $A D$, Liley $H$, Grant CA, Schibler A. Lung recruitment and endotracheal suction in ventilated preterm infants measured with electrical impedance tomography. J Paediatr Child Health. 2014:50(11):884-9.

3. Jauncey-Cooke Jl. Optimising paediatric ventilation. PhD Thesis, School of Nursing and Midwifery, The University of Queensland; 2012.

4. Main E, Castle R, Newham D, Stocks J. Respiratory physiotherapy vs. suction: the effects on respiratory function in ventilated infants and children. Intensive Care Med. 2004;30(6):1144-51. 
5. Elizabeth M, Yoel C, Ali M, Lubis M, GN Y. Comparison of ventilation parameters and blood gas analysis in mechanically-ventilated children who received chest physiotherapy and suctioning vs. suctioning alone. Paediatrica Indonesiana. 2016:56(5):285-90.

6. Bikker IG, van Bommel J, Reis Miranda D, Bakker J, Gommers D. Endexpiratory lung volume during mechanical ventilation: a comparison with reference values and the effect of positive end-expiratory pressure in intensive care unit patients with different lung conditions. Crit Care. 2008; 12(6):R145.

\section{Publisher's Note}

Springer Nature remains neutral with regard to jurisdictional claims in published maps and institutional affiliations.

Ready to submit your research? Choose BMC and benefit from:

- fast, convenient online submission

- thorough peer review by experienced researchers in your field

- rapid publication on acceptance

- support for research data, including large and complex data types

- gold Open Access which fosters wider collaboration and increased citations

- maximum visibility for your research: over $100 \mathrm{M}$ website views per year

At $\mathrm{BMC}$, research is always in progress.

Learn more biomedcentral.com/submissions 